American Journal of Pharmaceutical Education 2020; 84 (10) Article 7755.

\title{
BRIEF
}

\section{Evaluation of a Council Structure and Meeting Format for Pharmacy Student Government in the Co-Curriculum}

\author{
Sabrina Dunham, PharmD, ${ }^{\mathrm{a}, \mathrm{b}}$ Wendy C. Cox, PharmD, ${ }^{\mathrm{b}}$ Bradford L. Wingo, MEd, ${ }^{\mathrm{b}}$ \\ Jacqueline M. Zeeman, PharmD ${ }^{\mathrm{b}}$ \\ ${ }^{a}$ Tristar Centennial Medical Center/University of Tennessee College of Pharmacy in Nashville, Tennessee \\ $\mathrm{b}$ The University of North Carolina at Chapel Hill, UNC Eshelman School of Pharmacy, Chapel Hill, North Carolina \\ Submitted July 10, 2019; accepted May 31, 2020; published October 2020.
}

Objective. To evaluate student perceptions of a transformed pharmacy student government structure and meeting format.

Methods. The structure and general assembly meeting format of the University of North Carolina at Chapel Hill (UNC) Eshelman School of Pharmacy Student Senate (ie, student government) underwent a transformation from that of a forum to that of a council in an effort to address concerns regarding limited information exchange, minimal discussion, and unengaged meeting participants. To evaluate student perceptions of the new senate council format, members who attended at least one council meeting during the academic year were asked to complete a 12-item survey evaluating interorganizational relations, communication, collaboration, and efficiencies. Descriptive statistics were used to summarize students' agreement with 10 survey items. Thematic analysis was employed to identify common themes in students' responses to the two open-ended survey items.

Results. The majority of students agreed or strongly agreed that the senate council facilitated interorganizational relations $(86 \%)$, communication $(93 \%)$, and collaboration $(86 \%)$. Ninety-three percent of respondents agreed or strongly agreed that the senate council improved efficiencies, while $96 \%$ preferred the new senate council meeting format over the previous senate meeting format. Common qualitative themes included improved engagement during council meetings because of the "no laptop" policy and facilitation of open conversation by having a roundtable format and smaller number of members in attendance. Overall, $93 \%$ of students indicated they were satisfied or highly satisfied with the new meeting format.

Conclusion. Student perceptions suggest that the new senate council structure and meeting format was effective at improving interorganizational relations, communication, collaboration, and efficiencies within student body government.

Keywords: student government, student council, general assembly, student senate, co-curriculum

\section{INTRODUCTION}

Student government is a valuable institution within the academic infrastructure, established to represent student interests, enact and enforce policies pertaining to both academic and co-curricular activities, and facilitate student body interactions. ${ }^{1}$ Students elect peer representatives to serve in governance roles and participate in decision-

Corresponding Author: Jacqueline M. Zeeman, The University of North Carolina at Chapel Hill, UNC Eshelman School of Pharmacy, 326 Beard Hall, Chapel Hill, NC 27599. Tel: 919-966-0884. Email: jackie_zeeman@unc.edu Note: Note: Author Sabrina Dunham was a postgraduate year two cardiology pharmacy resident at Tristar Centennial Medical Center/University of Tennessee College of Pharmacy in Nashville, TN at the time of manuscript acceptance. making alongside school administration, faculty members, and staff members. ${ }^{2,3}$ Commonly, student government assists with overseeing student-driven activities, programs, and events embedded within student organizations. ${ }^{1}$ These initiatives are central to the school's culture and aid in developing leadership, professionalism, and other skills important in pharmacy practitioners. ${ }^{4}$

Recognizing the value of these important skills, the Accreditation Council for Pharmacy Education (ACPE) Standards 2016 place emphasis on the co-curriculum and posit that co-curricular activities should serve to augment or complement the skills, knowledge, and attitudes developed in the formal curriculum. ${ }^{5}$ As pharmacy schools develop a co-curriculum to comply with these standards, many may consider developing new programs or 


\section{American Journal of Pharmaceutical Education 2020; 84 (10) Article 7755.}

enhancing existing extracurricular opportunities, such as involvement in student organizations. ${ }^{6}$ When modifying previous student-driven extracurricular initiatives to fit new co-curricular models, it is important to optimize student government structure to ensure successful implementation and seamless alignment of the co-curriculum with program outcomes and accreditation standards. Optimizing student government structure is important for student government to successfully execute its responsibilities to represent, advocate, and support student-driven initiatives, including those within the co-curriculum (eg, student organizations).

Little is known about student government infrastructures and effective governance strategies. Kennedy and colleagues ${ }^{1}$ found that in 2015 some form of student government existed in $96 \%$ of US schools and colleges of pharmacy, with $75 \%$ of them charged to oversee the student body and student organizational activity. The study noted some general features of student government structure, including executive board composition, monthly meetings, and overall function, as well as that most pharmacy student government associations did not prohibit their officers from serving as leaders in other organizations. The authors remarked that the latter practice may lead to conflicts of interest and suggested that a house-of-delegates model could mitigate perceptions of bias and equalize representation. ${ }^{1}$ Student government plays an important role in complementing the co-curriculum of Doctor of Pharmacy (PharmD) programs, yet a gap in effective student government infrastructure to support students, student organizations, and the co-curriculum exists. ${ }^{1,7}$ The purpose of this study was to evaluate students' perceptions of a redesigned student government model and meeting format.

\section{METHODS}

The UNC Eshelman School of Pharmacy Student Senate (student government) previously employed a traditional general assembly structure to represent the student body. In addition to the student elected executive board, at least two representatives from each student organization and class year served on the senate. The senate met monthly in a stadium-style lecture hall where student leaders discussed relevant matters pertaining to students and student organizations, voiced student concerns, discussed student-led initiatives, and disseminated important information. Monthly meetings were reminiscent of a lectured-based teaching model rather than an interactive meeting, resulting in several limitations including unidirectional information sharing and unengaged meeting participants often distracted by their electronic devices. The meeting floor was open for discussion, but many students were reticent to share opinions or engage in meaningful conversation in a large, open-forum environment. Additionally, the individuals representing student organizations and each of the four classes enrolled often changed from month-to-month, resulting in communication and continuity challenges.

In efforts to address these perceived challenges, the Senate structure and meeting format was redesigned in August 2016. This change was student-driven, with administrative support provided by the School's Office of Curricular and Student Affairs (OCSA). Literature on organizational theory ${ }^{8}$ and educational practices, including student-centered active engagement strategies, ${ }^{9,10}$ informed our approach. Bolman and Deal ${ }^{8}$ describe a four-framed organizational model used to "reframe" the frameworks that cause organization inefficiencies. The idea is to examine situations using the four frames to identify barriers and improve processes within leadership and organizational design. The structural frame optimizes team structure and organization by examining the relationship between structure and environment; the human resource frame places people at the center of the organization and seeks to maximize interpersonal and group dynamics while supporting personal goals; the political frame recognizes political reality, manages power, and deals with conflict; and the symbolic frame gives purpose and meaning to actions. ${ }^{8}$ Applying Bolman's four-framed model, the student senate adapted the overall organization of members and roles (structural), shifted the meeting dynamics to build closer collaborative relationships (human resource), redefined the roles of senate members to foster more team-based governance (political), and created a culture of teamwork and transparency by redesigning the meetings and focusing the agendas to better address the needs of the student body (symbolic).

This new approach transformed the senate structure into a council comprised of elected student senate officers, class delegates, and student organization delegates. Senate officers were elected members of the student body (eg, student body president) and required to serve on the council as part of their role and responsibilities. One delegate from each class year (eg, the pharmacy year-1 president) and one delegate from each student organization (eg, the APhA-ASP leader) served on the council for one academic year. Each senate council member could only represent one student group in an effort to manage conflicting priorities across groups and avoid inequitable voting privileges. ${ }^{1}$ Delegates were responsible for representing the organization or class at the monthly council meeting; voting on behalf of the organization or class; updating the organization or class of council meeting discussions and outcomes; bringing forth new business to the council; and collaborating with all council members. The senate advisor served in an advisory role to the council and was the only non-student member. This measure was intentional to maintain the intimacy of the 


\section{American Journal of Pharmaceutical Education 2020; 84 (10) Article 7755.}

new structure, foster transparency, and promote studentdriven initiatives and student leadership.

In addition to embracing organizational theory, student-centered active engagement strategies also informed our approach. Literature on educational practices have shown that active engagement strategies (ie, studentcentered) have demonstrated higher levels of engagement and retention compared to traditional lecture-based (ie, instructor-based) models. ${ }^{9,10}$ In the new council model, senate meetings were taken out of the classroom and conducted in a round-table conference room to promote active engagement, relationship building, and communication. Leaders sat next to and across from each other in a smaller, more private venue in a closed-door session. Fifteen minutes of each council meeting was reserved for an open-door session that the student body could attend. Further, to afford flexibility for meeting length and member attendance, standing meetings were scheduled monthly after class hours (with dinner provided) to accommodate students' academic schedules. Evening meetings could be longer ( 90 minutes vs 60 minutes) and increased attendance opportunities for students located off campus (eg, those enrolled in experiential training). Additionally, other student meetings were not scheduled during council meetings. Steps to promote enthusiasm and engagement during council meetings included focused meeting agendas and discussion items, institution of a "no laptop" policy, and a policy revision to provide more time to review proposed changes prior to voting.

Restructuring the previous Senate into the new council had four primary objectives: improve interorganizational relations, improve communication, improve collaboration, and improve efficiencies. To evaluate student perceptions of the new council model and identify opportunities for future quality improvement, council members who attended at least one meeting during the 2016-2017 academic year $(n=29)$ were invited to complete a 12-item survey on Qualtrics (www.qualtrics.com). Descriptive statistics were used to summarize agreement frequencies among the 10 Likert-scale survey items. Two researchers reviewed qualitative responses and identified themes for the two opened-ended survey items: "Reflecting on the new Senate Council meeting format, what do you think has worked well?" and "Reflecting on the new Senate Council meeting format, what do you think are opportunities for improvement?" The UNC Institutional Review Board deemed this study exempt.

\section{RESULTS}

Ninety-seven percent of council members $(n=28)$ completed the survey. Based on their responses on a fourpoint Likert scale ranging from $1=$ strongly disagree to
$4=$ strongly agree, $96.4 \%$ of students agreed or strongly agreed that they preferred the new council meeting format over the former senate general body meeting and that the council meeting format facilitated the sharing of best practices in organizational planning and development (Table 1).

Compared to the former general body meeting format, the majority of respondents agreed or strongly agreed that the council meeting improved collaboration among student organizations (85.7\%), interorganizational relations $(85.7 \%)$, and dissemination of information $(82.1 \%)$. The majority of respondents also agreed or strongly agreed that the council meeting format provided an improved venue to voice organization opinions/concerns (96.4\%), voice overall student opinions/concerns $(85.7 \%)$, and facilitate interorganizational conversations that otherwise would not have occurred in the former general body meeting format $(92.9 \%)$. Reflecting on the council's objectives, $92.9 \%$ of respondents agreed or strongly agreed that the council met its goal to improve efficiencies (Table 1).

When asked to indicate their satisfaction with the council meeting format on a four-point Likert scale ranging from highly dissatisfied to highly satisfied, $92.9 \%$ reported being satisfied or highly satisfied. Common themes identified in the open-ended survey items included improved collaboration, communication, and engagement. Overall, students commented that they valued the smaller meeting size and that the use of assigned council delegates fostered stronger relationships among student organization leaders, and thus student organizations. Students also commented that the smaller meeting size and roundtable format facilitated improved communication and allowed for student leaders to share experiences and promote brainstorming and problemsolving on challenging topics or issues. Further, students commented that the no-laptop policy promoted engagement and that providing dinner facilitated a relaxed, open, and more pleasurable environment.

Those students who responded that they were dissatisfied $(7.1 \%)$ with the council meeting format suggested devoting more meeting time to implementing solutions, to improving student body participation in the open forum, and to devoting more time towards student organization updates, announcements, and/or requests. These themes were consistent with feedback provided by the $92.9 \%$ of students who reported being satisfied or highly satisfied with the council meeting format as well.

\section{DISCUSSION}

Student government is a common aspect of US schools and colleges of pharmacy and serves an important role. ${ }^{1}$ Students have an invested interest in their 


\section{American Journal of Pharmaceutical Education 2020; 84 (10) Article 7755.}

Table 1. Responses of Council Members to a Survey Regarding the Restructuring of the Format for Pharmacy Student Government in the Co-curriculum From a Senate General Assembly Format to a Senate Council Format

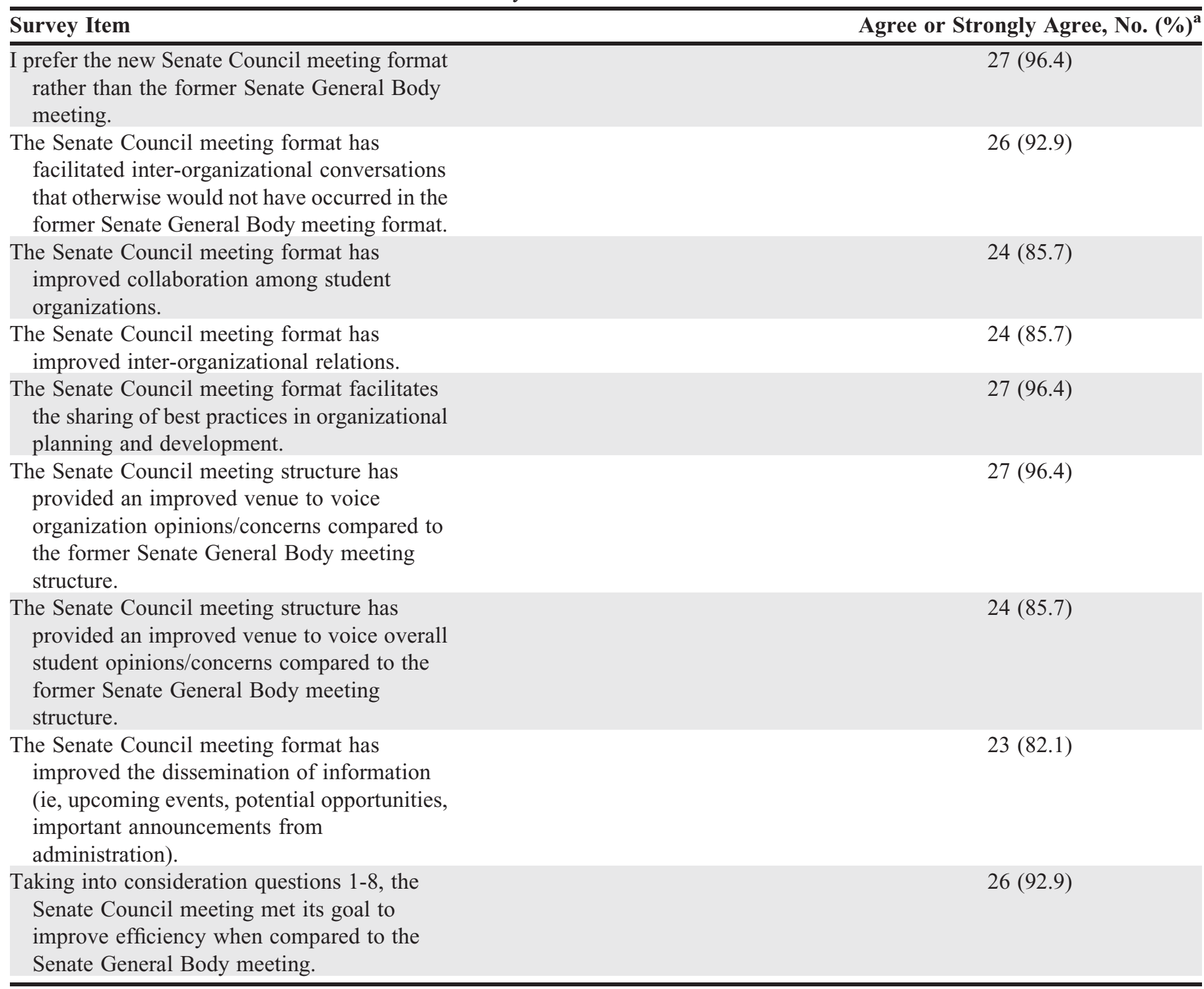

${ }^{a}$ Survey items measured on a four-point Likert scale: $1=$ strongly disagree, $2=$ disagree, $3=$ agree, and $4=$ strongly agree

educational and professional experiences and rely on peer representatives to ensure those interests are voiced and protected. ${ }^{2,3}$ Additionally, student government represents the student voice and facilitates student-led co-curricular initiatives, which play a key role in student leadership and professional skill development. ${ }^{4}$ However, a gap exists in identifying effective student government infrastructures. This study is one of the first to describe such, and the results of our study suggest that a council structure and meeting format may effectively support several fundamental tenets of a governing institution representing the interests of others, namely, inter-organizational relations, communication, collaboration, and efficiencies. Optimizing student government infrastructure and function can also help to ensure accreditation standards are met and create a forum for students to provide input on decisionmaking processes and issues affecting the student experience. ${ }^{1}$

Transforming a general assembly student government model into a leadership council with focused roles and responsibilities was met with positive feedback by council members. This model improved the overall quality of the senate (ie, improved communication, collaboration, inter-organizational relations) and may serve as an effective governance model for other professional programs.

While the majority of respondents preferred the council model over the former senate model, a weakness 


\section{American Journal of Pharmaceutical Education 2020; 84 (10) Article 7755.}

that persisted during the first-year of implementaiton was low participation by the general student body. In addition to the continued use of weekly email announcements and a school-wide events calendar, council delegates were encouraged to remind their organization members of council meetings. Further, other student organizations did not schedule meetings at the same time as council meetings to maximize student availability. Future use of social media outlets, text messaging, in-class announcements, or advertisements on school hallway screens may improve attendance.

Additional recommendations for improvement included spending more time during council meetings on brainstorming, discussing, and implementing solutions and devoting more time to providing general updates, making announcements, and holding discussions. These recommendations have continued to be focal points of consideration for each council, specifically at the start of each leadership year to ensure alignment with the council's goals and priorities.

Although positively received by students, this new meeting format was implemented at a single institution and its survey evaluation limited to one-year. However, subsequent surveys would have included students who had only experienced the new council format, and consequently would not have been able to make direct comparisons with the previous senate model. Further, while the council model was successfully implemented at this institution, implementation at other programs may differ given program's unique infrastructure, organization, oversight, and culture of both student organizations and student government. Additionally, future efforts may consider alternatives to sponsored monthly dinners as budgetary concerns have raised discussion about the sustainability of this amenity. To ensure the sustainability of the new council structure, council meetings have continued to be held in a boardroom in efforts to promote engagement and foster collaboration. Further, the council meetings continue to be held after hours to accommodate those students who may be located off campus. This continues to be well received by the council members and the student body and is considered an essential component of effective council operations.

The ACPE's Standards 2016 recognizes the value added by the co-curriculum and emphasizes how the cocurriculum complements the formal curriculum. ${ }^{5}$ Student governance can bolster the co-curriculum by facilitating student-identified educational and professional interests, and thus can be an asset in complying with this accreditation expectation. For example, student government representatives are best positioned to advocate on behalf of the student body for funding and/or resources from the school or university to support student- and student organization-driven programs that facilitate educational and professional development within the co-curriculum. These programs may include community outreach, professional development, leadership workshops, networking and career development, and student committee formation to advise on school or college initiatives. Findings suggest this model was effective at promoting better communication and collaboration among student leaders within student government. The council structure described here is one effective model that can be used by pharmacy schools for student government in the co-curriculum and can also help schools achieve co-curricular learning outcomes related to ACPE Standards 3 and 4 (eg, communication, leadership, professionalism). ${ }^{5}$

\section{CONCLUSION}

Student governance is important in academia and plays a vital role in facilitating co-curricular activities and initiatives important to the student experience. ${ }^{1-4}$ Although literature discussing the general importance of student government exists, ${ }^{1-3}$ best practices for pharmacy student governance are lacking. This study outlines a model to enhance pharmacy student government. By transforming an assembly-type structure into a council, the student government met its objectives to improve interorganizational relations, communication, collaboration, and efficiencies. These findings suggest a council format may be an effective approach to pharmacy student government and can serve as a model for other programs.

\section{ACKNOWLEDGMENTS}

The authors acknowledge the 2017 Student Senate Executive Board for their leadership and vision in the design and implementation of the senate council and the 2018 council members for their feedback and commitment to improving the newly implemented council model.

\section{REFERENCES}

1. Kennedy DR, Ginsburg DB, Harnois NJ, Spooner JJ. The role and responsibilities of pharmacy student government associations in pharmacy programs. Am J Pharm Educ. 2015;79(7):Article 100. 2. Zuo B, Ratsoy EW. Student participation in university governance. The Canadian Journal of Higher Education. 1999:29(1). 3. Love R, Miller M. Increasing student participation in selfgovernance: a comparison of graduate and undergraduate student perceptions. College Student Journal. 2003;37(4):532-544.

4. Zeeman JM, Bush AA, Cox CW, Buhlinger K, McLaughlin JE. Identifying and mapping skill development opportunities through pharmacy student organization. Am J Pharm Educ.

2019;83(4):Article 6950. 


\section{American Journal of Pharmaceutical Education 2020; 84 (10) Article 7755.}

5. Accreditation Council for Pharmacy Education (ACPE). Accreditation standards and key elements for the professional program in pharmacy leading to the doctor of pharmacy degree: Standards 2016.https://www.acpe-accredit.org/pdf/ Standards2016FINAL.pdf. Accessed September 28, 2020.

6. Patel UJ, Mediwala KM, Smith KM, Taylor S, Romanelli F. Carpe diem! seizing the rise of co-curricular activities. Am J Pharm Educ. 2017;81(8):Article 6702.

7. Ginsburg DB, Cox WC, Joyner PU, Lawson KA. An

exploration of student organizations in colleges of pharmacy.
International Journal of Pharmacy Education \& Practice. $2011 ;(1): 1-11$.

8. Bolman LG, Deal TE. Reframing Organizations. $4^{\text {th }}$ ed. San Francisco, CA: Jossey-Bass, A Wiley Imprint; 2008.

9. Bergmann J, Sams A. Flip Your Classroom: Reach Every Student in Every Class Every Day. Eugene, OR: International Society for Technology in Education; 2012.

10. Persky AM, McLaughlin JE. The flipped classroom - from theory to practice in health professional education. Am J Pharm Educ. 2017;81(6):Article 118. 